Çukurova Üniversitesi Mühendislik Mimarlık Fakültesi Dergisi, 31(2), 67-75 ss., Aralık 2016

Çukurova University Journal of the Faculty of Engineering and Architecture, 31(2), pp. 67-75, December 2016

\title{
Alkali ile Aktive Edilmiş Cüruf Harçlarının Yangın Direnci
}

\author{
Cahit BİLİM ${ }^{* 1}$ \\ ${ }^{1}$ Mersin Üniversitesi, Mühendislik Fakültesi, İnşaat Mühendisliği Bölümü, Mersin
}

Geliş tarihi: 01.06.2016 Kabul tarihi: 23.11 .2016

$\ddot{\mathbf{O z}}$

Çalışmada, alkali ile aktive edilmiş cüruf harçlarının yüksek sıcaklıklara maruz bırakılması sonrasındaki eğilme ve basınç mukavemetleri Portland çimentolu kontrol harcı ile kıyaslanmıştır. Öğütülmüş granüle yüksek firın cürufunun, ağırlıkça \%100 oranında çimento ile yer değiş̧tirilerek kullanıldığı çalışmada, harç karışımlarının su/bağlayıcı oranı 0,5 ve kum/bağlayıcı oranı 3,0 olmuştur. Cürufun aktivasyonunda, ağırlıkça cüruf miktarına göre $\% 4, \% 6$ ve $\% 8 \mathrm{Na}$ konsantrasyonlarındaki sıvı sodyum silikattan yararlanılmış olup, karışımlar içerisinde $0,75,1,0,1,25$ ve 1,5 gibi farklı silikat modülleri $\left(\mathrm{Ms}=\mathrm{SiO}_{2} / \mathrm{Na}_{2} \mathrm{O}\right)$ elde edebilmek amaciyla siv1 sodyum silikat, sodyum hidroksit ile beraber karıştııılmıştır. Ulaşılan bulgulardan, alkali ile aktive edilmiş cüruf harçlarının yangına karşı direncinin Portland çimentolu kontrol harcından daha iyi olduğu ve harçların yüksek sıcaklıklara karşı direncinin, uygulanan soğutma metodu ile sıcaklık seviyesine bağlı olduğu görülmüştür.

Anahtar Kelimeler: Alkali aktive edilmiş harç, Mukavemet, Yüksek sıcaklık, Sıvı sodyum silikat

\section{The Fire Resistance of Alkali-Activated Slag Mortars}

\begin{abstract}
In this study, the compressive and flexural strength of alkali activated slag mortars subjected to high temperatures were investigated, and the results obtained from the tests were compared with the control mortar. In the experiments, sand and water quantities were kept constant throughout the tests. Water/binder and sand/binder ratios were 0.5 and 3.0, respectively. Ground granulated blast furnace slag was used at $100 \%$ replacement by weight of cement in the tests. For slag activation, liquid sodium silicate at $4 \%, 6 \%$ and $8 \% \mathrm{Na}$ dosages was used, and liquid sodium silicate and sodium hydroxide were blended to obtain $0.75,1.00,1.25$ and 1.50 modulus ratio of $\mathrm{SiO}_{2} / \mathrm{Na}_{2} \mathrm{O}$. The findings showed that the fire resistance of alkali activated slag mortars were better than mortar with Portland cement. Additionally, the resistance of mortars to high-temperatures seemed to be dependent on temperature level and the cooling method.
\end{abstract}

Keywords: Alkali activated slag, Strength, High temperature, Liquid sodium silicate

\footnotetext{
*Sorumlu yazar (Corresponding author): Cahit BİLiM, cbilim@mersin.edu.tr
} 


\section{GíRiş}

Üretim maliyetlerini azaltmasının yanı sıra, betonun dayanım ve dayanıklılığı üzerindeki olumlu etkilerinden dolayı, günümüz beton teknolojisinde mineral katkıların kullanımı geniş bir yer tutmaktadır. Kullanılan bu mineral katkılardan birisi de, demir-çelik fabrikalarında pik demirin üretimi sırasında meydana gelen amorf yapıdaki granüle yüksek firın cüruflarıdır.

İnce öğütülmüş formda puzolanik özellik gösteren granüle yüksek firın cürufları, çimento endüstrisinde cüruflu çimento imalinde ya da normal Portland çimentosu (NPÇ) ile kısmi yer değiştirilerek mineral katkılı beton üretiminde kullanılmaktadır. Ancak, hidratasyon hizlarının yavaş seyretmesinden dolayı cüruf katkılı betonlarda görülen düşük erken mukavemet, bu tarz bağlayıcı kullanımını kısıtlamaktadır. Bu nedenle, ağır seyreden bu hidratasyon hızını yükselterek reaksiyonları hızlandırabilecek bir takım araştırmalar yapılmaktadır. Yürütülen çalışmalar, cürufların alkali aktivatörlerle birlikte kullanıldığı zaman, inşaat uygulamalarında kullanılabilecek tarzda güçlü bir bağlayıcı hamur yapısı meydana getirebileceğini ve böylelikle düşük erken mukavemet probleminin üstesinden gelinerek yüksek dayanım sağlanabileceğini göstermiştir [1].

Hiç çimento ilave etmeksizin, kimyasal aktivatör ve \%100 cüruf kullanmak suretiyle elde edilen alkali ile aktive edilmiş cüruflu (AAC) bağlayıcılar, sahip oldukları özellikler göz önüne alındığında, Portland çimentosuna alternatif modern bir bağlayıcı malzeme tipi olarak görülmektedir [2,3].

SSCB'den Glukhovsky tarafindan 1957 senesinde bulunmasına rağmen, dünya çapında ilgi görmesi birkaç y1l öncesine dayanan [4] ve artık günümüzde $\mathrm{ABD}$, Kanada, İngiltere, Avustralya, Rusya ve Çin gibi ülkelerde üzerinde önemli çalışmalar yapılan bu yeni yap1 malzemeleri, endüstriyel yan ürünlerin değerlendirilmesine imkân sağlamasının yanında, yüksek mekanik mukavemet, düşük enerji maliyeti ve NPÇ'na kıyasla daha az kirletici gaz $\left(\mathrm{CO}_{2}, \mathrm{SO}_{2}, \mathrm{NO}_{\mathrm{x}} \mathrm{vb}\right.$. $)$ emisyonu gibi avantajları ile karakterize edilmektedir [3].

Çok hızlı mekanik özellikler geliştirebilmeleri bakımından inşaat işlerindeki beklemeden ileri gelen kesinti ve aksaklıkları azaltma potansiyeli bulunan ve dolayısıyla, esas uygulama alanları onarım ve önceden dökülmüş yapı elemanları (beton borular, beton bloklar, ön gerilmeli beton kirişler ve betondan yapılmış duvar panelleri) olan AAC bağlayıcıları konusunda yapılan çeşitli araştırmalar, bu bağlayıcıların, NPÇ’na göre kimyasal atak ve donma-çözülme döngüleri gibi agresif ortam koşulları altında dahi üstün performans sergilediklerini göstermektedir $[5,6]$.

Bunun yanı sıra, Wang ve arkadaşları [7], NPÇ betonundan daha kaliteli beton üretebilmek için AAC'un etkili bir bağlayıcı olduğunu rapor etmiştir. Cüruflu çimentoların alkali aktivasyonu üzerine çalışmalar yapan Bakharev ve arkadaşları [8], sodyum hidroksit ve sodyum karbonat ile karşılaştırıldığında, sıvı sodyum silikatın basınç mukavemeti açısından en iyi aktivasyonu verdiğini bildirerek 0,75 silikat modülüne sahip ve $\% 4$ konsantrasyondaki sıvı sodyum silikat kullanımını önermişlerdir. Jiménez ve arkadaşları [9], AAC harçlarının mekanik özelliklerinin gelişimi üzerinde bir dizi faktörün etkilerini araştırdıkları çalışmalarında, en yüksek mekanik özellikleri veren faktörün siv1 sodyum silikat ve sodyum hidroksit olduğunu, diğer önemli faktörlerin ise aktivatör dozaj1 ve sonrasında da cüruf özgül yüzeyi ile kür sıcaklığı olduğunu rapor etmişlerdir. Atiş ve arkadaşları [10], AAC harçlarından en yüksek eğilme ve basınç mukavemeti değerleri elde edebilmek için sıvı sodyum silikat çözeltisinin optimum bir $\mathrm{SiO}_{2} / \mathrm{Na}_{2} \mathrm{O}$ oranının olduğunu belirtmişlerdir. $1000^{\circ} \mathrm{C}$ sıcaklığa maruz bırakılan AAC harçları üzerinde bir araştırma yürüten Karahan ve Yakupoğlu [11], NPÇ harcına kıyasla, sodyum hidroksit kullanılarak üretilen $\mathrm{AAC}$ harçlarının üstün bir yangın direnci sergilediğini bildirmişlerdir. Al-Otaibi [12], AAC betonların üretiminde aktivatörün yüksek dozaj ve silikat modülüne sahip olmasının yüksek mukavemet verdiğini, bu nedenle de aktivatör tip ve dozajının önem taşıdığı sonucuna varmış, AAC betonlarının NPÇ betonları ile karşılaştırıldığında zor çevre 
koşulları altında üstün durabilite sergilediğini rapor etmiştir.

Görüldüğü üzere, AAC bağlayıcıları üzerinde birçok araştırmalar yapılmış olmasına karşın bu bağlayıcıların yangın direnci konusunda kapsamlı ve dikkate değer bir çalışmaya ulaşılamamıştır. Dolayısıyla bu çalışmada, yüksek sıcaklıklara maruz bırakılan AAC harçlarının eğilme ve basınç mukavemetleri araştırılarak elde edilen sonuçlar rapor edilmiştir.

\section{DENEYSEL ÇALIŞMA}

\subsection{Kullanılan Malzemeler ve Özellikleri}

\subsection{1. Çimento}

Çalışmada, kimyasal kompozisyonu Çizelge 1'de verilmiş olan TS EN 197-1 [13] ile uyumlu CEM I 42,5 R Portland çimentosu kullanılmıştır. Özgül ağırlığ $3,16 \mathrm{~g} / \mathrm{cm}^{3}$ ve özgül yüzeyi $315 \mathrm{~m}^{2} / \mathrm{kg}$ olan çimentonun, başlangıç ve bitiş priz süreleri sirasıyla, 197 ve 248 dakikadır.

Çizelge 1. Çimento ve cürufun kimyasal özellikleri

\begin{tabular}{|l|c|c|}
\hline Oksit & Çimento & Cüruf \\
\hline $\mathrm{SiO}_{2}$ & 14,20 & 33,78 \\
\hline $\mathrm{Al}_{2} \mathrm{O}_{3}$ & 3,64 & 9,55 \\
\hline $\mathrm{Fe}_{2} \mathrm{O}_{3}$ & 4,71 & 0,88 \\
\hline $\mathrm{CaO}$ & 66,49 & 39,80 \\
\hline $\mathrm{MgO}$ & 1,73 & 6,80 \\
\hline $\mathrm{SO}_{3}$ & 4,10 & 1,66 \\
\hline $\mathrm{K}_{2} \mathrm{O}$ & 0,88 & 0,88 \\
\hline $\mathrm{Na}_{2} \mathrm{O}$ & 0,11 & 0,32 \\
\hline $\mathrm{K} . \mathrm{K}$ & 1,35 & 2,89 \\
\hline
\end{tabular}

\subsubsection{Granüle yüksek firın cürufu}

Çalışmada, OYAK Adana Çimento Sanayi'nden temin edilen ve kimyasal kompozisyonu Çizelge 1 'de verilmiş olan ögütülmüş granüle yüksek firın cürufu kullanılmıştır. Cürufun özgül ağırlığı $2,78 \mathrm{~g} / \mathrm{cm}^{3}$, Blaine özgül yüzeyi ise $5200 \mathrm{~cm}^{2} / \mathrm{g}$ dir.

Şekil 1'de ise bu iki malzemeye ait lazer kırınım yöntemi ile elde edilen tane boyut dağılımı verilmiştir.

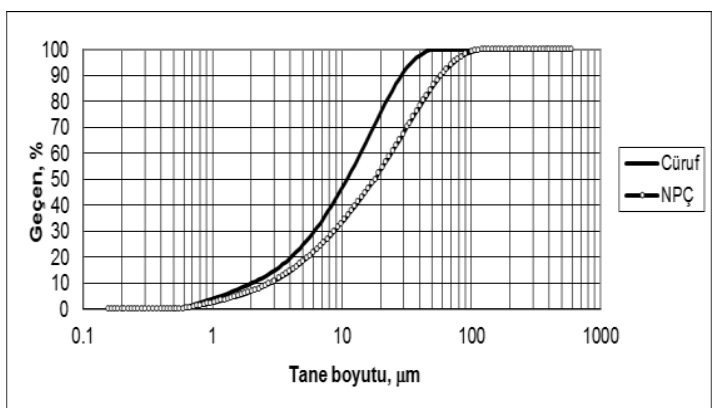

Şekil 1. Kullanılan çimento ve cürufun tane büyüklük dağılımı

\subsubsection{Kum}

Harç karışımlarının hazırlanmasında TS EN 196-1 [14] ile uyumlu CEN standart kumu kullanılmıştır.

\subsubsection{Su}

Karışım suyu olarak şehir şebekesinden alınan içilebilir musluk suyundan yararlanılmıştır.

\subsubsection{Alkali Aktivatör}

Yürütülen çalışmada, öğütülmüş granüle yüksek firın cürufunun aktivasyonu için alkali aktivatör olarak, 2.0 modül siv1 sodyum silikat kullanılmıştır.

\subsection{Deneysel Program}

Çalışmada, yüksek sıcaklıklara maruz bırakılan AAC harçlarının mekanik özellikleri üzerinde $\mathrm{Na}$ dozaj1 ve silikat modülü gibi aktivatör parametrelerinin etkileri araştırılmıştır.

$\mathrm{Su} /$ bağlayıcı oranı 0,5 ve kum/bağlayıcı oranı 3,0 olacak şekilde hazırlanan harç karışımlarında, öğütülmüş granüle yüksek firın cürufu, ağırlıkça \%100 oranında çimento ile yer değiştirilerek kullanılmıştır. Cürufun aktivasyonunda ise ağırlıkça cüruf miktarına göre $\% 4, \% 6$ ve $\% 8 \mathrm{Na}$ konsantrasyonlarındaki sıvı sodyum silikattan yararlanılmış olup, karışımlar içerisinde 0,75, 1,0, 1,25 ve 1,5 gibi farklı silikat modülleri $\left(\mathrm{Ms}=\mathrm{SiO}_{2} / \mathrm{Na}_{2} \mathrm{O}\right)$ elde edebilmek amaciyla siv1 sodyum silikat, sodyum hidroksit ile beraber karıştırılmıştır. Aktivatörlerin, su içerisinde 
çözülmek suretiyle karışımlara eklendiği deneylerde, su/bağlayıcı madde oranının sabit tutulması için, aktivatör çözeltisinin ihtiva ettiği su miktarı göz önüne alınmış ve karışımlara eklenecek su miktarlarında eksiltme yoluyla ayarlamaya gidilmiştir. Şekil 2'de gösterilen çimento mikseri yardımıyla belirtilen malzeme oranlarında hazırlanan ve biri tamamen NPÇ karışım olmak üzere toplam 13 grup karışımdan, $40 \times 40 \times 160 \mathrm{~mm}$ boyutlarında prizmatik harç numuneleri üretilmiştir.

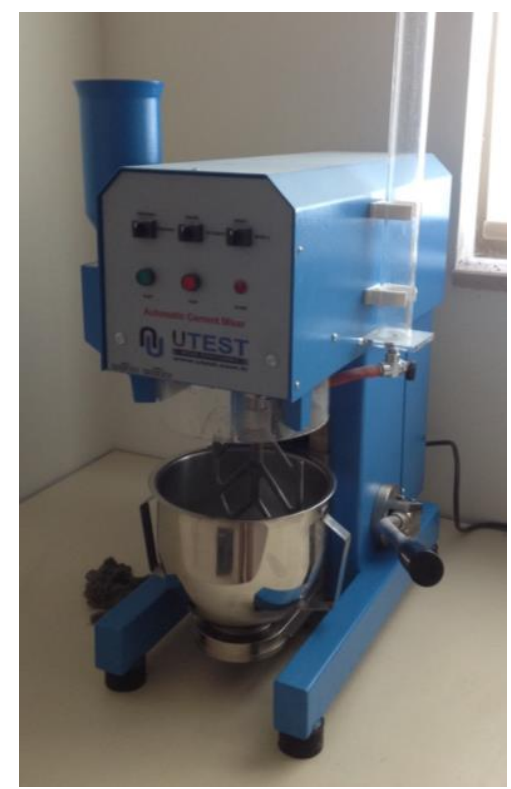

Şekil 2. Çimento mikseri

Dökümden 24 saat sonra kalıplarından çıkartılan numuneler, $21 \pm 1^{\circ} \mathrm{C}$ sicaklıktaki su içerisinde 27 gün boyunca kür edilmişlerdir. Kür süresi sonunda her bir karışımdan 6 adet prizmatik numune, Şekil 3 'teki yüksek sıcaklık firını içerisinde 1 saat süre ile $300^{\circ} \mathrm{C}, 600^{\circ} \mathrm{C}$ ve $900^{\circ} \mathrm{C}$ sicakliklara maruz bırakılmıştır. Isıtma hızının $5^{\circ} \mathrm{C} / \mathrm{dk}$ olarak ayarlandığı deneylerde sıcak harç numuneleri firından çıkartıldıktan hemen sonra iki farklı şekilde soğutulmuştur. Birincisinde, her grubun 3 adet numunesi 1 saat boyunca $21 \pm 1^{\circ} \mathrm{C}$ sicaklıktaki su içerisinde hızlı bir şekilde soğutulurken ikincisinde ise, grupların diğer 3 adet numunesi, 1 saat boyunca laboratuvar ortamında yavaş bir şekilde havada soğumaya bırakılmıştır. Soğutma işleminin ardından, numunelerin TS EN 1015-11 [15]'e göre eğilme ve basınç dayanımları Şekil 4 'te gösterilen çimento test presi yardımıyla belirlenmiş, ulaşılan sonuçlar ortalaması alınarak, yüksek sıcaklığa maruz bırakılmamış kontrol numunelerininki ile kıyaslanmıştır.

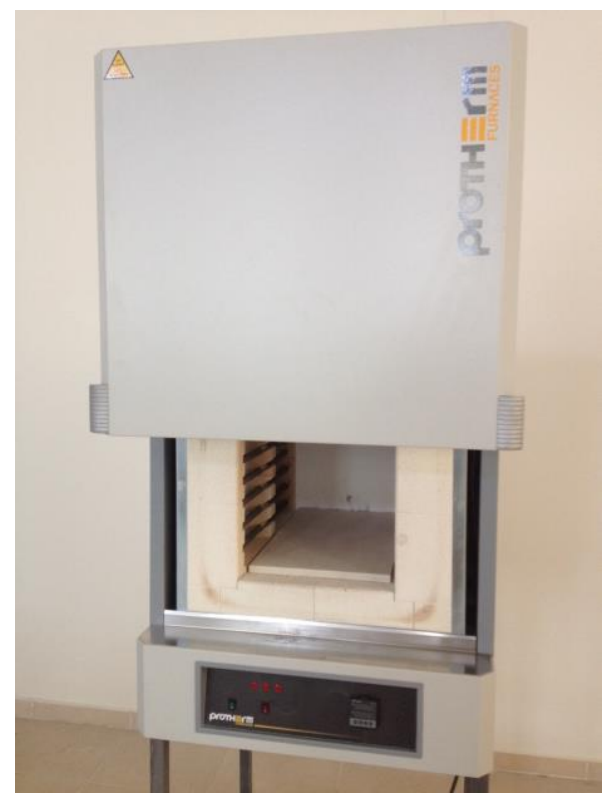

Şekil 3. Yüksek sıcaklık fırını

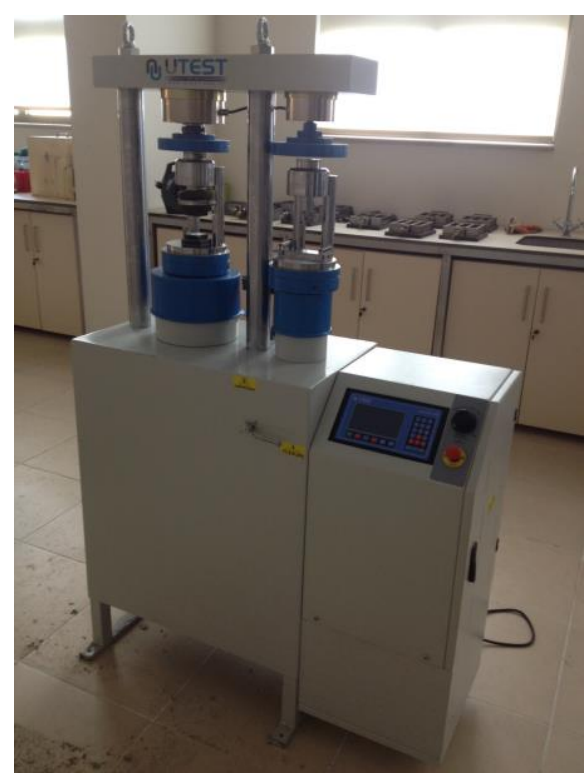

Şekil 4. Çimento test presi 
Çalışmada kullanılan karışım programı Çizelge 2'de gösterilmiştir.

Çizelge 2. Karışım programı

\begin{tabular}{|lcccc|}
\hline Karışım & Çimento & Cüruf & Dozaj & Ms \\
\hline NPÇ & $\% 100$ & - & - & - \\
\hline AAC 1 & - & $\% 100$ & $\% 4 \mathrm{Na}$ & 0,75 \\
AAC 2 & - & $\% 100$ & $\% 4 \mathrm{Na}$ & 1,00 \\
AAC 3 & - & $\% 100$ & $\% 4 \mathrm{Na}$ & 1,25 \\
AAC 4 & - & $\% 100$ & $\% 4 \mathrm{Na}$ & 1,50 \\
\hline AAC 5 & - & $\% 100$ & $\% 6 \mathrm{Na}$ & 0,75 \\
AAC 6 & - & $\% 100$ & $\% 6 \mathrm{Na}$ & 1,00 \\
AAC 7 & - & $\% 100$ & $\% 6 \mathrm{Na}$ & 1,25 \\
AAC 8 & - & $\% 100$ & $\% 6 \mathrm{Na}$ & 1,50 \\
\hline AAC 9 & - & $\% 100$ & $\% 8 \mathrm{Na}$ & 0,75 \\
AAC 10 & - & $\% 100$ & $\% 8 \mathrm{Na}$ & 1,00 \\
AAC 11 & - & $\% 100$ & $\% 8 \mathrm{Na}$ & 1,25 \\
AAC 12 & - & $\% 100$ & $\% 8 \mathrm{Na}$ & 1,50 \\
\hline
\end{tabular}

\section{BULGULAR VE TARTIŞMA}

\subsection{Harçların Yüksek Sıcaklık Sonrasındaki Basınç Mukavemetleri}

Harç numunelerin 28 günlük kür süresinin ardından $300-900^{\circ} \mathrm{C}$ arasında değişen yüksek sıcaklıklara maruz bırakılması sonrasında elde edilen basınç mukavemetleri, Çizelge 3'te sunulmuştur.

Çizelge 3'ten görüldüğü üzere, AAC harç numunelerinin basınç mukavemeti değerleri, alkali aktivatörün artan $\mathrm{Na}$ dozajı ile birlikte artış göstermiştir. Örneğin, AAC 3, AAC 7, AAC 11 harçlarının $20^{\circ} \mathrm{C}$ 'deki basınç mukavemeti değerleri sirasiyla 6,06 $\mathrm{MPa}, 73,16 \mathrm{MPa}$ ve $83,51 \mathrm{MPa}$ olmuştur. $\mathrm{Bu}$ durum, sodyum dozajındaki artıştan dolayı cüruf aktivasyonunun hızlanmasına bağlı olarak ortaya çıkan daha yoğun mikro yapı ile ilgilidir [16]. AAC harçlarının mikro yapısal gelişimi çoğunlukla cürufun anyonları ile alkali aktivatörün katyonları arasındaki reaksiyondan ileri gelmektedir. İyon değişimi sonucu ortaya çıkan bu kimyasal reaksiyonlar, silika jellerini meydana getirmekte, cürufun kalsiyum iyonlarının da ilave reaksiyonları ile birlikte bu silika jelleri
C-S-H jellerine dönüşmektedir $[17,18]$. Bunun yanı sıra, Ms modülünün 0,75 'ten 1,5'a doğru artış göstermesi, AAC harç numunelerinin basınç mukavemeti değerlerini olumlu yönde etkilemiştir. Örneğin, AAC 5, AAC 6, AAC 7 ve AAC 8 harç numunelerinin $20^{\circ} \mathrm{C}$ 'deki basınç mukavemeti değerleri sırasıyla 68,85 $\mathrm{MPa}, 70,61 \mathrm{MPa}$, $73,16 \mathrm{MPa}$ ve 75,94 $\mathrm{MPa}$ olmuştur. Bu bulgular, başka makalelerde rapor edilenler ile de uyum içerisindedir $[19,20]$.

Çizelge 3 'te, $300^{\circ} \mathrm{C}$ sıcaklık sonrasında havada soğutulmuş harç numunelerinin basınç mukavemetinde $\quad 20^{\circ} \mathrm{C}$ sicaklıktaki harç numunelerine kıyasla bir artış gözlenmiştir. Havada soğutulmuş harçlar ele alınırsa, $20^{\circ} \mathrm{C}$ normal sicaklıktaki harçlara kıyasla $300^{\circ} \mathrm{C}$ sıcaklıktaki harçların basınç mukavemetlerindeki artış \%7 ile \%206 arasında değişmiş ve maksimum mukavemet artışı \%4 $\mathrm{Na}$ içeriğine sahip AAC harçlarında gözlenmiştir. $300^{\circ} \mathrm{C}$ dereceye kadar olan bu mukavemet artış1, serbest suyun buharlaşması neticesinde matris içerisindeki jel tabakalarının birbirlerine daha da yaklaşarak daha büyük van der Waals kuvvetleriyle çekmesinden kaynaklanmaktadır [21-23]. Ayrıca bu durum, alkali aktivatör ile cüruf arasındaki kimyasal reaksiyonların yüksek sicaklığa bağlı olarak hızlanması neticesinde meydana gelen daha yoğun bağlayıcı madde hamurunun yapısıyla da ilişkilidir. Bununla birlikte, $600^{\circ} \mathrm{C}$ sıcaklığa gelindiğinde harçların basınç mukavemeti değerlerinde kayıplar meydana gelmeye başlamış ve bu kayıplar, sicaklık $900^{\circ} \mathrm{C}$ olduğunda önemli mertebelere ulaşmıştır. Harç numunelerin basınç mukavemetlerinde ortaya çıkan bu kayıplar, C-S-H jellerinin dağılmasından ileri gelmektedir [24,25].

Diğer taraftan, havada yavaş soğutmaya göre su içerisinde hızlı soğutma, basınç dayanımlarında ilave kayıplara yol açmış ve NPÇ ile yapılan harç numuneler $900^{\circ} \mathrm{C}$ sicaklıkta tamamen parçalanmıştır. $\mathrm{Bu}$ durum, ani sıcaklık farklılıklarından kaynaklanan termal şokun bir sonucu olarak ortaya çıkan mikro çatlakların gelişimine atfedilebilir. Ayrıca, $400-500^{\circ} \mathrm{C}$ sicaklığın üzerinde $\mathrm{Ca}(\mathrm{OH})_{2}$ suyunun kaybederek $\mathrm{CaO}$ 'e dönüşür. Eğer $\mathrm{CaO}$ su ile temas ederse büyük bir hacim artışıla birlikte $\mathrm{Ca}(\mathrm{OH})_{2}$ 
Çizelge 3. Harçların basınç mukavemeti

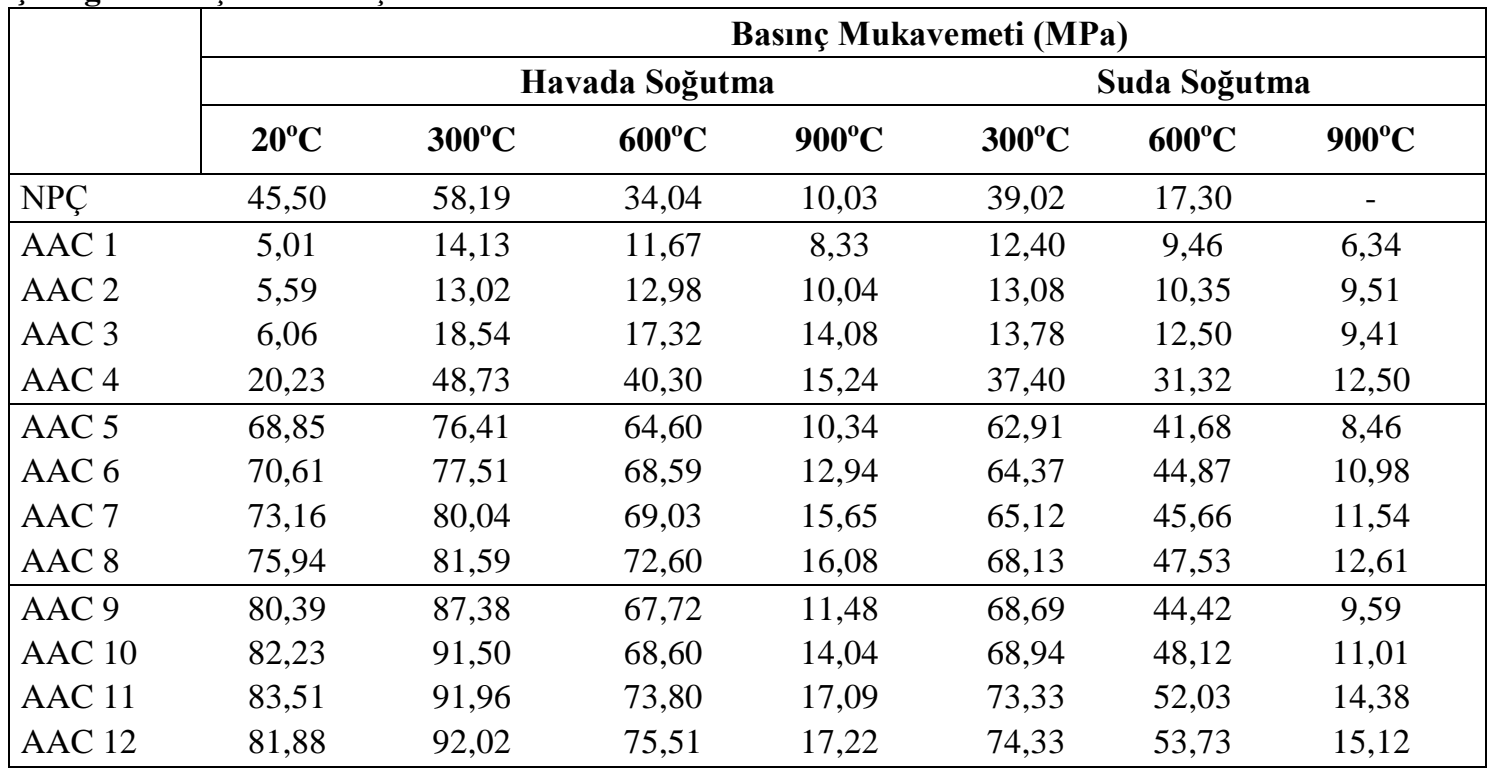

meydana gelir [26,27]. Bununla birlikte, hizlı ve yavaş soğutma arasındaki mukavemet farklılıklarının $900^{\circ} \mathrm{C}$ 'de azaldığı gözlenmiştir. $\mathrm{Bu}$ durum, $600^{\circ} \mathrm{C}$ ve yukarısındaki sıcaklıklarda ortaya çıkan çok sayıda mikro çatlağın varlığı ile ilişkilidir [28].

Çizelge 3 incelendiğinde, AAC harç numunelerinin basınç mukavemeti değerlerinin çoğu durumda NPÇ harçlarınınkinden daha yüksek olduğu görülmüştür. $\mathrm{Bu}$ durum, yüksek sıcaklıklara maruz bırakılan NPÇ harçlarındaki durabilite kayıplarının ana sebebi olan $\mathrm{Ca}(\mathrm{OH})_{2}$ 'in AAC harçlarında bulunmamasından kaynaklanmaktadır [29].

\subsection{Harçların Yüksek Sıcaklık Sonrasındaki Eğilme Mukavemetleri}

Harç numunelerin 28 günlük kür süresinin ardından $300-900^{\circ} \mathrm{C}$ arasında değişen yüksek sicaklıklara maruz birakılması sonrasında elde edilen eğilme mukavemetleri, Çizelge 4'te sunulmuştur.

Çizelge 4'ten görüleceği üzere, eğilme mukavemeti üzerinde, yüksek sıcaklıkların zararlı etkisi, basınç dayanımındaki durumdan daha şiddetli olmuştur. Havada soğutulmuş harçların tümünün basınç dayanımı, $300^{\circ} \mathrm{C}$ sıcaklığa kadar artış göstermesine karşın, $300^{\circ} \mathrm{C}$ sicaklıktan itibaren karışımlar eğilme mukavemetlerinin birazını kaybetmeye başlamıştır. Bu durum şu şekilde açıklanabilir: Numunenin merkezi ile yüzeyi arasındaki önemli sıcaklık farklılıkları, termal çatlakları meydana getirir [30]. Bu termal çatlakların mevcudiyeti, sağlam kesit alanını azaltır ve eğilme testine maruz bırakılan numunelerde tarafsız eksenin altında kalan kısımlarında meydana gelen çekme gerilmeleri çatlakların büyüklüğünde bir artış ortaya çıkartır [31-33]. Bu yüzden, çatlakların eğilme mukavemeti değerleri üzerindeki olumsuz etkisi basınç mukavemeti değerlerinden daha belirgin olmaktadır.

Hızlı soğutmanın yol açtığı ani sıcaklık değişimlerinin bir sonucu olarak ortaya çıkan mikro çatlakların varlığından dolayı, suda soğutulan harç numunelerinin eğilme mukavemeti değerleri, havada yavaş soğutulan harç numunelerininkinden daha düşük olmuştur. Bununla birlikte, AAC harçlarının eğilme mukavemeti değerleri aktivatör $\mathrm{Na}$ konsantrasyonun yükselmesi ile birlikte artış göstermiştir. Örneğin $300^{\circ} \mathrm{C}$ sıcaklık sonrasındaki 
Çizelge 4. Harçların eğilme mukavemeti

\begin{tabular}{|c|c|c|c|c|c|c|c|}
\hline & \multicolumn{7}{|c|}{ Eğilme Mukavemeti (MPa) } \\
\hline & \multirow[b]{2}{*}{$20^{\circ} \mathrm{C}$} & \multicolumn{3}{|c|}{ Havada Soğutma } & \multicolumn{3}{|c|}{ Suda Soğutma } \\
\hline & & $300^{\circ} \mathrm{C}$ & $600^{\circ} \mathrm{C}$ & $900^{\circ} \mathrm{C}$ & $300^{\circ} \mathrm{C}$ & $600^{\circ} \mathrm{C}$ & $900^{\circ} \mathrm{C}$ \\
\hline NPÇ & 9,02 & 8,19 & 3,09 & 0,82 & 5,62 & 1,27 & - \\
\hline AAC 1 & 2,48 & 1,73 & 1,01 & 0,34 & 1,36 & 0,50 & 0,29 \\
\hline AAC 2 & 2,77 & 2,04 & 1,03 & 0,46 & 1,77 & 0,54 & 0,34 \\
\hline AAC 3 & 3,05 & 2,69 & 1,32 & 0,49 & 2,04 & 0,84 & 0,42 \\
\hline $\mathrm{AAC} 4$ & 4,64 & 3,12 & 2,43 & 0,56 & 2,50 & 1,16 & 0,47 \\
\hline AAC 5 & 5,79 & 2,88 & 1,76 & 0,45 & 2,30 & 0,92 & 0,34 \\
\hline AAC 6 & 6,02 & 3,14 & 2,01 & 0,49 & 2,51 & 1,31 & 0,41 \\
\hline AAC 7 & 6,27 & 3,35 & 2,46 & 0,73 & 2,80 & 1,41 & 0,52 \\
\hline AAC 8 & 6,70 & 3,66 & 2,50 & 0,84 & 3,02 & 1,55 & 0,68 \\
\hline AAC 9 & 6,09 & 3,21 & 1,83 & 0,63 & 2,57 & 0,89 & 0,40 \\
\hline AAC 10 & 6,17 & 3,45 & 2,16 & 0,74 & 2,83 & 1,56 & 0,53 \\
\hline AAC 11 & 6,75 & 3,51 & 2,74 & 0,83 & 2,83 & 1,68 & 0,68 \\
\hline AAC 12 & 6,88 & 3,79 & 3,05 & 0,90 & 3,15 & 1,72 & 0,75 \\
\hline
\end{tabular}

AAC 2 harcının eğilme mukavemeti 2,04 $\mathrm{MPa}$ iken, AAC 7 ve AAC 11 karışımları için eğilme mukavemeti değerleri sırasıyla 3,35 ve 3,51 $\mathrm{MPa}$ olmuştur. Benzer durum, Ms silikat modülündeki artış sonucunda da gözlenmiştir. Örneğin, $20^{\circ} \mathrm{C}$ 'de AAC 9, AAC 10, AAC 11 ve AAC 12 harçlarının eğilme mukavemeti değerleri, silikat modülündeki artış ile birlikte yükselme göstererek sırasıyla 6,09, 6,17, 6,75 ve 6,88 MPa olmuştur. Diğer taraftan, AAC harçlarının yüksek sıcaklıklar sonrasında geriye kalan eğilme dayanımları, genel olarak NPÇ içeren harç numunelere göre düşük olmuştur. Ancak, yüksek Na dozajı ve Ms modülü, özellikle $600^{\circ} \mathrm{C}$ ve yukarısı gibi yüksek sıcaklıklar sonrasındaki eğilme dayanımlarında ortaya çıkan kayıpların azalmasında yarar sağlamıştır.

\section{SONUÇLAR}

Yapılan bu laboratuvar çalışmasından elde edilen sonuçlar aşağıda özetlenmiştir;

1. Havada soğutma yöntemine kıyasla, suda ani soğutma yöntemi, çatlak gelişmesine neden olması bakımından harç dayanımlarında düşüşler meydana getirmiştir.

2. Yüksek sıcaklıkların zararlı etkisi, basınç dayanımındaki durum ile karşılaştırıldığında eğilme mukavemeti üzerinde daha belirgin ve şiddetli olmuştur.

3. Aktivatör $\mathrm{Na}$ konsantrasyonun yükselmesi, silikat modülünde yapılan artışta olduğu gibi, AAC harçlarının yangına karşı direncini arttırmıştır.

4. AAC harçlarının yangına karşı direncinin NPÇ içeren harcınkinden daha iyi olduğu görülmüş ve harçların yüksek sıcaklıklara karş1 direncinin, uygulanan soğutma metodu ile sıcaklık seviyesine bağlı olduğu tespit edilmiştir.

5. $\mathrm{Bu}$ araştırmanın kapsamında yer almayan, ancak farklı kimyasal aktivatörlerin ve kür koşullarının etkilerini içeren başka çalışmaların da yapılması, AAC bağlayıcıların yüksek sıcaklık ve yangına karşı direncinin araştırılmasında yarar sağlayacaktır. 


\section{TEŞEKKÜR}

Yazar bu çalışmaya finansal destek sağlayan Mersin Üniversitesi Araştırma Projeleri Birimine (Proje No: BAP-MÜH F İMB (CB) 2012-7 A) teşekkür eder.

\section{KAYNAKLAR}

1. Collins, F.G., Sanjayan, J.G., 1999. Workability and Mechanical Properties of Alkali Activated Slag Concrete, Cement and Concrete Research, Vol. 29, No. 3, pp. 455458.

2. Chang, J.J., Yeih, W., Hung, C.C., 2005. Effects of Gypsum and Phosphoric Acid on the Properties of Sodium Silicate-Based AlkaliActivated Slag Pastes, Cement and Concrete Composites, Vol. 27, No. 1, pp. 85-91.

3. Puertas, F., Amat, T., Jiménez, A. F., Vázquez, T., 2003. Mechanical and Durable Behaviour of Alkaline Cement Mortars Reinforced With Polypropylene Fibres, Cement and Concrete Research, Vol. 33, No. 12, pp. 2031-2036.

4. Wang, S. D., 2000. The Role of Sodium During Hydration of Alkali-Activated Slag, Advances in Cement Research, Vol. 12, No. 2, pp. 65-69.

5. Palacios, M., Puertas, F., 2007. Effect of Shrinkage-Reducing Admixtures on the Properties of Alkali-Activated Slag Pastes and Mortars, Cement and Concrete Research, Vol. 37, No. 5, pp. 691-702.

6. Neto, A. A. M., Cincotto, M. A., Repette, W., 2008. Drying and Autogenous Shrinkage of Pastes and Mortars With Activated Slag Cement, Cement and Concrete Research, Vol. 38, No. 4, pp. 565-574.

7. Wang, S. D, Pu, X. C, Scrivener, K. L, Pratt, P. L., 1995. Alkali-Activated Slag Cement and Concrete: A Review of Properties and Problems, Advances in Cement Research, Vol. 7, No. 27, pp. 93-102.

8. Bakharev, T., Sanjayan, J.G, Cheng, Y., 1999. Alkali Activation of Australian Slag Cements, Cement and Concrete Research, Vol. 29, No. 1, pp. 113-120.
9. Jiménez, A.F., Palomo, J.G., Puertas, F., 1999. Alkali-Activated Slag Mortars: Mechanical Strength Behavior, Cement and Concrete Research, Vol. 29, No. 8, pp. 1313-1321.

10. Atis, C.D., Bilim, C., Çelik, Ö., Karahan, O., 2009. Influence of Activator on the Strength and Drying Shrinkage of Alkali-Activated Slag Mortar, Construction and Building Materials, Vol. 23, No. 1, pp. 548-555.

11. Karahan, O., Yakupoğlu, A., 2011. Resistance of Alkali-Activated Slag Mortar to Abrasion and Fire, Advances in Cement Research, Vol. 23, No. 6, pp. 289-297.

12. Al-Otaibi, S., 2008. Durability of Concrete İncorporating GGBS Activated by WaterGlass, Construction and Building Materials, Vol. 22, No. 10, pp. 2059-2067.

13. TS EN 197-1, 2012. Çimento - Bölüm 1: Genel Çimentolar - Bileşim, Özellikler ve Uygunluk Kriterleri, Türk Standartları Enstitüsü, Ankara.

14. TS EN 196-1, 2009. Çimento Deney Metotları - Bölüm 1: Dayanım Tayini, Türk Standartları Enstitüsü, Ankara.

15. TS EN 1015-11, 2000. Kâgir Harcı Deney Metotlar1-Bölüm 11: Sertleşmiş Harcın Basınç ve Eğilme Dayanımının Tayini, Türk Standartları Enstitüsü, Ankara.

16. Bilim, C., Karahan, O., Atiş, C. D, İlkentapar, S., 2015. Effects of Chemical Admixtures and Curing Conditions on Some Properties of Alkali-Activated Cementless Slag Mixtures, KSCE Journal of Civil Engineering, Vol. 19, No. 3, pp. 733-741.

17. Yang, K. H., Song, J. K., Ashour, A. F., Lee,E.T., 2008. Properties of Cementless Mortars Activated by Sodium Silicate, Construction and Building Materials, Vol. 22, No. 9, pp. 1981-1989.

18. Bilim, C., Karahan, O., Atiş, C. D., İlkentapar, S., 2013. Influence of Admixtures on the Properties of Alkali-Activated Slag Mortars Subjected to Different Curing Conditions, Materials \& Design, Vol. 44, pp. 540-547.

19. Aydın, S., Baradan, B., 2012. Mechanical and Microstructural Properties of Heat Cured Alkali-Activated Slag Mortars, Materials \& Design, Vol. 35, pp. 374-383.

20. Krizan, D., Zivanovic, B., 2002. Effects of Dosage and Modulus of Water Glass on Early 
Hydration of Alkali-Slag Cements, Cement and Concrete Research, Vol. 32, No. 8, pp. 11811188.

21. Khoury, G. A., 1992. Compressive Strength of Concrete at High Temperatures: A Reassessment, Magazine of Concrete Research, Vol. 44, No. 161, pp. 291-309.

22. Dias, W.P.S., Khoury, G.A., Sullivan, P.J.E., 1990. Mechanical Properties of Hardened Cement Paste Exposed to Temperatures up to $700^{\circ} \mathrm{C}$, ACI Materials Journal Vol. 87, No. 2, pp. 160-166.

23. Hossain, K.M.A., 2006. High Strength Blended Cement Concrete Incorporating Volcanic Ash: Performance at High Temperatures, Cement and Concrete Composites, Vol. 28, No. 6, pp. 535-545.

24. Xu, Y., Wong, Y.L., Poon, C.S., Anson, M., 2001. Impact of High Temperature on PFA Concrete, Cement and Concrete Research, Vol. 31, No. 7, pp. 1065-1073.

25. Poon, C.S., Azhar, S., Anson, M., Wong, Y.L., 2001. Comparison of the Strength and Durability Performance of Normal and HighStrength Pozzolanic Concretes at Elevated Temperatures, Cement and Concrete Research, Vol. 31, No. 9, pp. 1291-1300.

26. Aydin, S., 2008. Development of a HighTemperature-Resistant Mortar by Using Slag and Pumice, Fire Safety Journal, Vol. 43, No. 8, pp. 610-617.

27. Bilim, C., 2014. Influence of Clinoptilolite Replacement on Durability of Cement Mortars, Journal of Materials in Civil Engineering, Vol. 26, No. 3, pp. 520-526.

28. Mohamedbhai, G.T.G., 1986. Effect of Exposure Time and Rates of Heating and Cooling on Residual Strength of Heated Concrete, Magazine of Concrete Research, Vol. 38, No. 136, pp. 151-158.

29. Guerrieri, M., Sanjayan, J., Collins, F., 2009. Residual Compressive Behavior of AlkaliActivated Concrete Exposed to Elevated Temperatures, Fire Materials, Vol. 33, No. 1, pp. 51-62.

30. Kong, D.L.Y., Sanjayan, J.G., 2010. Effect of Elevated Temperatures on Geopolymer Paste, Mortar and Concrete, Cement and Concrete Research, Vol. 40, No. 2, pp. 334-339.
31. Xu, Y., Wong, Y.L., Poon, C.S., Anson, M., 2003. Influence of PFA on Cracking of Concrete and Cement Paste After Exposure to High Temperatures, Cement and Concrete Research, Vol. 33, No. 12, pp. 2009-2016.

32. Özturan, T., Cülfik, M. S., 2002. Effect of Elevated Temperatures on the Residual Mechanical Properties of High-Performance Mortar, Cement and Concrete Resarch, Vol. 32, No. 5, pp. 809-816.

33. Li, M., Qian, C., Sun, W., 2004. Mechanical Properties of High Strength Concrete After Fire, Cement and Concrete Research, Vol. 34, No. 6, pp. 1001-1005. 
